\title{
Reply to: Comment on: “Using Field Based Data to Model Sprint Track Cycling Performance"
}

Hamish Ferguson ${ }^{1 *}$, Chris Harnish ${ }^{2}$ and Geoff Chase $^{3}$

\section{Dear Editor,}

We thank Dr. Douglas [1] for his interest in our literature review outlining our current understanding of sprint cycling [2]. In our review, we use existing data to propose a new, more comprehensive model for sprint cycling performance, to which we recently added more evidence to support this hypothesized model [3]. In his letter [1], Dr. Douglas lays out specific criticisms of our "data" and recommendations by creating a strawman argument. However, much of what he argues against was never actually written in our literature review.

For example, our work [2] never states aerobic training should be prioritized, arguing instead that aerobic training is likely undervalued and a mixture of training may be required. More specifically, our literature review presents a broad swathe of the available data, although not every paper available, as any good review does, and then presents an interpretation and recommendations based on that literature. Specifically, our review makes the case that peak power output (PPO) measures and sprint training alone may limit both assessment and training of sprint cyclists. We also contend sprint cycling should consider the potential contributions of aerobic training to improve performance, and in fact PPO. Dr. Douglas' fundamental claim is essentially based on the idea any aerobic training limits PPO and thus performance [1]. We feel the data disagree and, equally, state several times more research is needed [2].

This response clarifies aspects of our review which have not been clearly interpreted.

\footnotetext{
This comment refers to the article available at https://doi.org/10.1186/ s40798-021-00348-0.

* Correspondence: hamish.ferguson@pg.canterbury.ac.nz

${ }^{1}$ Centre for Bioengineering, Department of Mechanical Engineering,

University of Canterbury, Private Bag 4800, Christchurch 8140, New Zealand Full list of author information is available at the end of the article
}

\section{Peak Power is a Clear Part of Sprint Performance}

Our literature review [2] never suggests PPO is not a component of sprint cycling performance, and nor do we assert it should not be an objective of training. Our review highlights the current lack of data beyond piecemeal studies examining individual components of sprinting. Dorel et al. [4] focused on the flying 200-m component of the sprint event, which is one race of 912 races over a 1-2-day period. Phillips and Hopkins [5] focused on the relationships between the flying 200-m time and the overall outcomes, which ignores the tactical components of the sprint event. We fail to see how $74 \%$ of PPO explains $30 \mathrm{~s}$ Wingate test performance, when only correlation analysis was used [6], and compared to data showing counter movement jump, seated Wingate PPO and seated Wingate average power for $30 \mathrm{~s}$ only explained $41-66 \%$ of performance of the starting straight in BMX [7]. Our use of Figs. 2 and 3 in our review [2] describe the performance envelope of the flying $200-\mathrm{m}$ and of a sprint race, not as anecdote or proof, and it is misleading to state this is our intention as all peer reviewers did not read it this way. More directly, it is clear PPO explains only a large fraction, but far from all, of sprint performance, a gap being addressed in our review.

In particular, our review challenges current sprint cycling models solely based on PPO $[4,8]$. We recently published data [3] showing a strong relationship between 15-s and 30-s power and power at $2 \mathrm{~min}, 8 \mathrm{~min}$, and $20 \mathrm{~min}$. In a public debate, instigated by Cycling New Zealand with author HF, Dr. Douglas presented data claiming a near perfect relationship between PPO and 30-s power using a chart based on high performance data [9]. We compared these data to our data and found the claimed relationships were stronger between our data using national level sprinters and the high performance sprinters than the near 1:1 relationship claimed (Fig. 1a). Figure 1b 


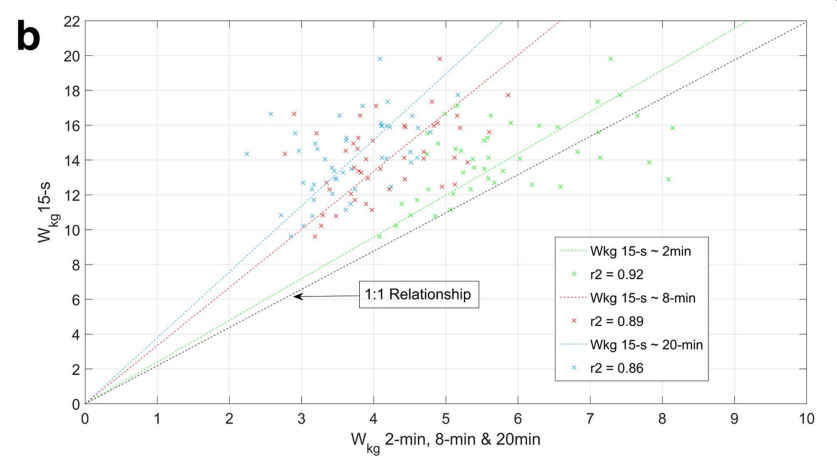

Fig. 1 b A comparison of $15 \mathrm{~s} W_{\mathrm{kg}}$ with three durations that rely on oxidative energetic supply. All data are from national level sprint cyclists and show very high correlations of $R^{2}=0.86-0.92$, showing strong inter-relationships of endurance and power

further demonstrates the strong inter-relationship of peak power and oxidative energy system intervals of 2-20 $\mathrm{min}$ with $R^{2}=0.86-0.92$ [3], which are far higher than the correlations of PPO and short period Wingate tests $[6,7]$. These very recent results further validate our point that sprint performance is not strictly a function of $\mathrm{PPO}$, whereas if this conjecture of Dr. Douglas' was true, correlation of PPO would be very low for these longer intervals. It is not.

We refer Dr. Douglas to the many recent works showing the importance of PPO to sprint cycling performance to assure him we are not dismissing the concept [1013], but are instead moderating it towards a hybrid approach as suggested by the data and relevant literature and analysis in our review.

\section{Track Cycling Sprinting is Multiple Sprint Performance}

We wish to make it clear; we did not refer to track cycling sprinting as repeated sprint exercise [2]. All track cycling sprint events require multiple races in a day. We are not deterred in this area of investigation by a single subject case study that does not present data from all sprints [14], nor by a study which provides no PPO data, and actually supports our contention that the oxidative system becomes increasingly involved in later efforts in the multiple sprint protocol [15]. Our review [2] highlighted the absence of actual data from sprint cycling competition and directed the reader towards studies using a sprint and recovery duration similar to sprint competition, where there were performance drops after a $30-60-$ min recovery period $[16-18]$.

\section{Summary}

We believe our review [2] summarizes the current state of research and presents a reasonable interpretation, as all good reviews should. Our review argues PPO alone is an insufficient model to account for a track cycling sprint race, let alone a race series involving several races over a day, all of which is supported by data. Our review thus highlights both the well-established critical power model [19] and the anaerobic speed reserve model [20]; suggests, in turn, that these models are not complete; and proposes there may be models better reflecting the physiology and demands of sprint cycling. From this point, we propose a more comprehensive approach may be required to better prepare sprint cyclists, based on the available data, including both PPO and oxidative energy systems training.

Authors' contributions

$\mathrm{HF}$ wrote the original draft, and $\mathrm{HF}, \mathrm{CH}$ and GC equally contributed to the editing. All authors read and approved the final manuscript.

Funding

No sources of funding were used to assist in the preparation of this letter.

\section{Declarations}

Competing Interests

The authors, Hamish Ferguson, Chris Harnish, and Geoff Chase, declare that they have no competing interests.

\section{Author details}

${ }^{1}$ Centre for Bioengineering, Department of Mechanical Engineering, University of Canterbury, Private Bag 4800, Christchurch 8140, New Zealand. ${ }^{2}$ Department of Exercise Science, College of Health, Mary Baldwin University, Staunton, VA, USA. ${ }^{3}$ Centre for Bioengineering, Department of Mechanical Engineering, University of Canterbury, Private Bag 4800, Christchurch 8140, New Zealand.

Published online: 23 August 2021

References

1. Douglas J. Comment on: Using field based data to model sprint track cycling performance. Sports Med - Open. 2021;7(1):20.

2. Ferguson $\mathrm{HA}$, Harnish $\mathrm{C}$, Chase JG. Using field based data to model sprint track cycling performance. Sports Med - Open. 2021;7(1):20.

3. Ferguson HA, Zhou T, Harnish C, et al. Model of 30-s sprint cycling performance: Don't forget the aerobic contribution! 11th IFAC Symposium on Biological and Medical Systems (BMS 2021), Ghent, Belgium, Sept 19-22, 
6-pages (Benyo, B, Ed) IN: IFAC PapersOnLine. Open Access: In-Press; 2021. (Available on request from authors)

4. Dorel S, Hautier C, Rambaud O, et al. Torque and power-velocity relationships in cycling: relevance to track sprint performance in world-class cyclists. Int J Sports Med. 2005;26(9):739-46.

5. Phillips KE, Hopkins WG. Factors affecting cyclists' chances of success in match-sprint tournaments. Int I Sports Physiol Perform. 2018:1-20.

6. Inbar O, Kaiser P, Tesch P. Relationships between leg muscle fiber type distribution and leg exercise performance. Int J Sports Med. 1981;2:154-9.

7. Bertucci $W$, Hourdé $C$. Laboratory testing and field performance in BMX riders. J Sports Sci Med. 2011;10(2):417-9.

8. Martin JC, Gardner AS, Barras M, et al. Modeling sprint cycling using fieldderived parameters and forward integration. Med Sci Sport Exerc. 2006; 38(3):592-7.

9. Cycling New Zealand. Debate: Sprint Coaching. Avanti Lounge 1, Avantidrome, Cambridge, New Zealand 12:30pm, 2021;April 21.

10. Kordi M, Goodall S, Barratt $\mathrm{P}$, et al. Relation between peak power output in sprint cycling and maximum voluntary isometric torque production. J Electromyogr Kinesiol. 2017;35:95-9.

11. Kordi M, Menzies C, Parker SL. Relationship between power-duration parameters and mechanical and anthropometric properties of the thigh in elite cyclists. Eur J Appl Physiol. 2018;118(3):637-45.

12. Kordi M, Folland J, Goodall S, et al. Reliability of traditional and task specific reference tasks to assess peak muscle activation during two different sprint cycling tests. J Electromyogr Kinesiol. 2019;46:41-8.

13. Kordi M, Folland J, Goodall S, et al. Mechanical and morphological determinants of peak power output in elite cyclists. Scand J Med Sci Sports. 2020;30(2):227-37.

14. Klich S, Krymski I, Kawczyński A. Viscoelastic properties of lower extremity muscles after elite track cycling sprint events: a case report. Centr Eur J Sport Sci Med. 2020;29(1):5-10

15. Louis J, Billaut F, Bernad T, et al. Physiological demands of a simulated BMX competition. Int J Sports Med. 2013;34(06):491-6.

16. Lindsay A, Petersen C, Blackwell G, et al. The effect of 1 week of repeated ischaemic leg preconditioning on simulated Keirin cycling performance: a randomised trial. BMJ Open Sports Med. 2017;3(1):e000229.

17. Zabala M, Requena B, Muñoz C, et al. Effects of sodium bicarbonate ingestion on performance and perceptual responses in a laboratorysimulated BMX cycling qualification series. J Strength Cond Res. 2008;22: 1645-53.

18. Zabala M, Peinado A, Calderón F, et al. Bicarbonate ingestion has no ergogenic effect on consecutive all out sprint tests in BMX elite cyclists. Eur J Appl Physiol. 2011;111:3127-34.

19. Morton RH. The critical power and related whole-body bioenergetic models. Eur J Appl Physiol. 2006;96(4):339-54.

20. Weyand PG, Lin JE, Bundle MW. Sprint performance-duration relationships are set by the fractional duration of external force application. Am J PhysiolReg. 2006;290(3):R758-65.

\section{Publisher's Note}

Springer Nature remains neutral with regard to jurisdictional claims in published maps and institutional affiliations.

\section{Submit your manuscript to a SpringerOpen ${ }^{\circ}$ journal and benefit from:}

- Convenient online submission

- Rigorous peer review

- Open access: articles freely available online

- High visibility within the field

- Retaining the copyright to your article

Submit your next manuscript at $\boldsymbol{\nabla}$ springeropen.com 